\title{
Divided Nations: Why global governance is failing, and what we can do about it
}

[LS blogs.Ise.ac.uk/europpblog/2013/07/17/divided-nations-why-global-governance-is-failing-and-what-we-can-doabout-it/

Globalisation has made the world a far more interconnected place than ever before. lan Goldin writes that while this increased connectivity provides unprecedented opportunities for collaboration and innovation, it also risks facilitating the spread of global crises. Meeting these globalised challenges will require a radical rethinking of global governance structures, with five core principles being at the heart of any successful reform process.

The financial crisis that started in 2008 was the first of the systemic crises of the $21^{\text {st }}$ Century. It will not be the last. The collapse of a relatively small asset market spread with alarming speed and ferocity; the contagion swept across the world, reaching areas only tangentially connected to the financial hubs of New York and London.

Shortly after the global financial meltdown, the first case of Swine Flu (H1N1) was recorded in Mexico. A month later, there were confirmed cases in the US, Canada, Spain, the United Kingdom, Israel, and New Zealand. By June 2009 , less than three months after the first case, more than 25,000 documented cases were recorded in 74 countries and at least 15,000 deaths were confirmed. The Center for Disease Control in Atlanta estimates that as many as 300,000 people died from the strain worldwide. We were lucky. Had the disease been more like Spanish Influenza of the early $20^{\text {th }}$ Century, millions or hundreds of millions would have perished.

These globalised challenges reflect the rising potential for cascading risk. This is the underbelly of globalisation. Climate change, cyber attacks, pandemics, antibiotic resistance and global financial meltdowns-to name a feware no longer abstract specters, they are the defining challenges of our time. Now, more than ever, we inhabit a global village. Yet we lack competent village elders to guide us. While an alphabet soup of regional and global organisations exists, an effective system of global governance that is prepared to deal with $21^{\text {st }}$ Century challenges does not. This must change.

Such change does not imply the end of national sovereignty or a radical challenge to local autonomy and legitimacy. For local problems that can be confined and dealt with inside borders, the intervention of global entities is unwarranted and unwelcome. But we live in an era that does involve problems that have no regard for national boundaries. Such challenges require coordination and agreements that invariably mean giving up some national sovereignty and ascribing to rules which bind different countries together. Piecemeal national efforts without coordination have been and will continue to be impotent in the face of systemic threats that transcend national borders.

As I argue in my book, Divided Nations, the stakes for getting it right have never been so high. But the omens

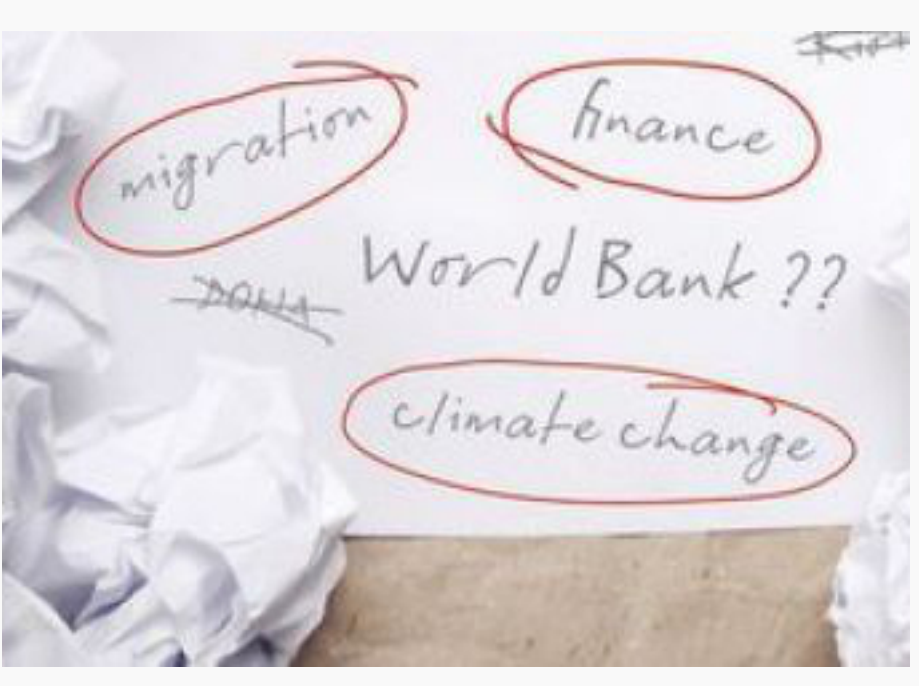

Divided Nations, Credit: Oxford University Press are not good. If past decades provide a guide, new problems will simply be thrown at old institutions, created for other purposes. The UN, IMF, World Bank, and others are overloaded and cannot deliver on their mushrooming mandates. We need to redesign global governance, 
ensuring that well-defined manageable mandates are applied to existing organisations, that new institutions are established when old ones cannot cope, and that coordination across governing bodies from local to regional or global is both constant and effective. The establishment of a shared system of rules to promote inclusive and sustainable globalisation is urgently needed.

The past offers cause for pessimism. Far too often, the push to establish new institutions or reform global governance is born in the wake of tragedy-just as the UN and Bretton Woods institutions rose phoenix-like from the ashes of World War II. In too many instances, global tragedy is the currency paid to invest in global governance reform.

I am an optimist and believe that increased physical and virtual connectivity has led to the most rapid economic and social progress humanity has ever known. It provides unprecedented opportunity to collaborate and innovate. From the crumbling of ideological and economic walls could come a century which, for the first time, is characterised by a world free of poverty and disease, resting on a shared commitment to manage our global commons. Without action, however, those same avenues for cooperation and collaboration could prove to be the infrastructure for unprecedented destruction and devastation-not only for the progress of recent centuries, but also the environment that underpins life on our planet.

Yesterday's structures are not equipped to deal with today's problems, but thankfully it is not too late. Aggressive action must be taken, and such action would be effective if it incorporates five core principles which I have developed together with my Oxford colleague, Ngaire Woods. First, global action is only required on global problems. Local jurisdictions matter and should continue to address local and national problems on their own terms. Second, while not everyone must be included in global negotiations, inclusion of key actors is essential. It is an obvious point that if the biggest polluters are left out of climate change agreements, the agreement is useless-but this principle must be central to any reform efforts.

Third, efficiency is essential. Unwieldy bodies that include everyone are worse than nimble, exclusive bodies that involve the key players. Who are the key players? It depends on the issue. The small island nation of the Maldives, sinking from rising sea levels, should not be included in questions about regulating climate change but must be included on negotiations about mitigating its impacts. If small groups of key countries with much at stake are involved, gridlock can be broken.

Fourth, legitimacy is required for effective global governance. A system must be in place wherein countries may disagree with certain rules of the game, but accept the referees. Fifth, enforceability is paramount. None of these principles matter if they cannot be enforced.

Global governance is the challenge of our time. Our arsenal of stale institutions cannot cope with existing threats to peace, stability, and prosperity. Whether we like it or not, we are all in this together. It's time we start acting like it.

This article draws on material in Divided Nations: Why global governance is failing and what we can do about it (Oxford University Press, 2013).

Please read our comments policy before commenting.

Note: This article gives the views of the author, and not the position of EUROPP - European Politics and Policy, nor of the London School of Economics.

Shortened URL for this post: http://bit.ly/12ByVpm

\section{About the author}


Ian Goldin - University of Oxford

Ian Goldin is Director of the Oxford Martin School and Professor of Globalization and Development at the University of Oxford. His recent books include Divided Nations: Why global governance is failing and what we can do about it (Oxford University Press, 2013), Globalization for Development: Meeting New Challenges (Oxford University Press, 2012), and Exceptional People: How Migration Shaped our World and Will Define our Future (Princeton University Press, 2011).

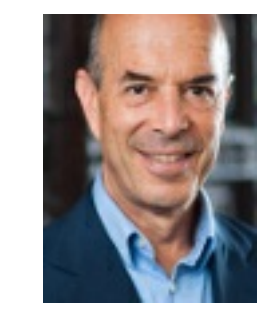

